\title{
Textile Environmental Conditioning: Effect of Relative Humidity Variation on the Tensile Properties of Different Fabrics
}

\author{
Mansoor Iqbal, Munazza Sohail, Aleem Ahmed, Kamran Ahmed, Arsheen Moiz, Khalil Ahmed* \\ Applied Chemistry Research Centre, PCSIR Laboratories Complex, Karachi, Pakistan. \\ Email: ${ }^{*}$ khalilmsrc@gmail.com
}

Received December 25 ${ }^{\text {th }}, 2011$; revised January $7^{\text {th }}$, 2012; accepted January $31^{\text {st }}, 2012$

\begin{abstract}
With the aim that to confirm the need for humidity control in the environment in which textile sample are visually and instrumentally analyzed, three different pre-conditioned fabrics sample of cotton, polyester and silk were treated at a fix temperature of $21^{\circ} \mathrm{C}$. The relative humidity adjusted to four levels: $55 \%, 65 \%, 75 \%$ and $85 \% \mathrm{RH}$ for a conditioning time of 24 hours as specified in ASTM D-1776-98. It has been observed that as the relative humidity increase from 55\% to $85 \%$ cotton increase its tensile strength, silk losses its strength and there was no significant change observed in the tensile strength of polyester fabric.
\end{abstract}

Keywords: Tensile Properties; Relative Humidity; Temperature; Fiber; Silk; Polyester; Cotton

\section{Introduction}

The properties of textile fibers are in many cases strongly affected by the atmospheric moisture content. Many fibers, particularly the natural ones are hygroscopic in the sense that they are able to absorb water vapour from a moist atmosphere and to give up water to a dry atmosphere. If sufficient time is allowed, equilibrium will be reached. The amount of moisture that such fiber contains strongly affects many of their most important physical properties [1]. Many physical properties of a fiber are affected by the amount of water absorbed such as dimensions, tensile strength, elastic recovery, electrical resistance, rigidity and so on. When in fabric from the moisture relationships of a fiber play a major part in deciding whether the fabric is unsuitable for a particular purpose. The importance of this point is appreciated when fabrics for clothing, both outerwear and underwear, are considered additional factors arise in these cases since the structural details of the can modify the apparent behavior of the fiber [2]. In an orderly array of molecules the side chain will be linked, but in a random arrangement a number of free links or hooks will be available, and if they are of a polar character i.e. possess an attraction of polar chemical groups such as hydroxyl $\mathrm{OH}$, carboxyl $\mathrm{COOH}$, carbonyl $\mathrm{CO}$ etc, then water molecule can attach themselves. Orderly arrays of molecules occur in the

\footnotetext{
${ }^{*}$ Corresponding author.
}

crystalline region of the fiber structure and random arrays in the amorphous region. For a first approximation we could conclude that the absorption of water takes place in the amorphous region [3]. An alternative definition for Relative Humidity (RH) is the absolute humidity of the air to that of air saturated with water vapour at the same temperature and pressure. This ratio may then be expressed as a percentage. At ordinary temperatures such as those at which processing and testing are carried out the two ratios are almost identical. It is convenient to describe a given atmosphere in term of relative humidity rather than absolute humidity because the region of textile materials appears depends upon the relative humidity rather than the actual amount of water vapour present. Since the relative humidity affect the region of textile materials and since the properties of textile materials influenced by the region. It is necessary to specify the atmospheric condition in which testing should be carried out [4]. Because of the important changes that occur in textile properties as the moisture content changes, it is necessary to specify atmospheric condition in which any testing carried out. Therefore a standard atmosphere has been agreed for testing purposes and is defined as a relative humidity of $65 \%$ and a temperature of $20^{\circ} \mathrm{C}$. For practical purposes certain tolerances in these values are allowed so that for testing atmosphere the RH is $65 \% \pm$ $2 \%, 20^{\circ} \mathrm{C} \pm 2^{\circ} \mathrm{C}$. In tropical region a temperature of $27^{\circ} \mathrm{C}$ $\pm 2^{\circ} \mathrm{C}$ may be used [5]. Even though a testing laboratory may have a controlled atmosphere, it is not good practice 
to take in samples and immediately start to test them. Sufficient time should be allowed for the sample to reach equilibrium conditions before the test are made. A preconditioning is therefore required specially before tensile testing at $50^{\circ} \mathrm{C}$ and $25 \% \mathrm{RH}$ for 4 hours. Breaking strength or tensile strength is the maximum force recorded in extending a test piece to breaking point. It is the figure that is generally referred to as strength. The force at which a specimen breaks is directly proportional to its cross-sectional area, therefore when comparing the strength of different fibers, fabrics allowances have to be made for this. The tensile force recorded at the moment of rupture is sometimes referred to as the tensile strength at break [6]. In the present study we are trying to evaluate the effect of RH at different levels on tensile strength of polyester, cotton and silk fibers.

\section{Materials \& Methods}

\subsection{Material}

Scoured and bleached, optical brightener free plain weave cotton, silk and polyester fabric were used as given in Table 1.

\subsection{Equipments}

To obtain the required relative humidity \& temperature, Conditioning Chamber (Denco, England) was used. For pre-conditioning of fabrics, Associated Environmental System (SDL Atlas, England) was used. Tensile strength of the fabric was carried out on CRE Tensile Testing Machine (LRX Plus, LLOYD). Fabric weight was determined on G.S.M Cutter (Hans Schmidt \& Co. Germany). End \& Picks were determined by Pick Glass (Waltex 6X pick glass).

\subsection{Procedure}

- Pre-conditioning of all the fabrics were carried out in Associated Environmental System of SDL Atlas at $50^{\circ} \mathrm{C}$ and $25 \% \mathrm{RH}$ for 4 hrs [5].

- Conditioning of samples was done in Conditioning Chamber of DENCO England at 55\%, 65\%, 75\% and $85 \% \mathrm{RH}$ and $21^{\circ} \mathrm{C}$ for $24 \mathrm{hrs}$ [5].

- For Tensile Strength determination take two sets of test specimen one in warp and other in weft direction. Threads should be removed in approximately equal numbers from each of the long edges of the cut strip until the width of the test specimen is achieved. Each set consist of at least 5-test specimen each should be $50 \mathrm{~mm}$ in width and $200 \mathrm{~mm}$ length. Tensile Strength of fabric was determined according to standard test procedure ISO 13934-1 (1999). [7]

- Fabric Weight was determined according to standard test procedure ISO 3801 (1977)-E [8].

- $\quad$ Ends \& Picks were determined by ISO 7211-2 (1984) [9]

\section{Results and Discussion}

To determine that how different levels of relative humidity can affect on the tensile properties of fabrics, three different fabrics cotton, polyester and silk were first preconditioned at $50^{\circ} \mathrm{C}$ at $25 \%$ R.H, then they again undergoes to conditioning at 55\%, 65\%, 75\% and $85 \%$ for different levels of $\mathrm{RH}$ and at $21^{\circ} \mathrm{C}$ temperature. It has been observed that different fibers shows different behavior in terms of tensile strength under the same conditions of RH and temperature. Shown in Table 2 and Figure 1, as we passes from 55\% to $85 \%$ RH, cotton

Table 1. Fabric weight and construction.

\begin{tabular}{ccc}
\hline Fabric & GSM $\left(\mathbf{g} / \mathbf{m}^{2}\right)$ & Construction \\
\hline Cotton & $132 \mathrm{~g} / \mathrm{m}^{2}$ & $22 * 22 / 80 * 58$ \\
Polyester & $110.92 \mathrm{~g} / \mathrm{m}^{2}$ & $60 * 30 / 140 * 72$ \\
Silk & $70.01 \mathrm{~g} / \mathrm{m}^{2}$ & $102 * 102 / 187 * 69$ \\
\hline
\end{tabular}

Table 2. For $100 \%$ cotton (tensile strength both in warp \& weft direction at different $\mathrm{RH}$ values).

\begin{tabular}{cccccc}
\hline & RH & $\mathbf{5 5 \%}$ & $\mathbf{6 5 \%}$ & $\mathbf{7 5 \%}$ & $\mathbf{8 5 \%}$ \\
\cline { 2 - 6 } $\mathbf{S} \#$ & Temperature & $\mathbf{2 1}^{\circ} \mathbf{C}$ & $\mathbf{2 1}^{\circ} \mathbf{C}$ & $\mathbf{2 1}^{\circ} \mathbf{C}$ & $\mathbf{2 1}^{\circ} \mathbf{C}$ \\
\cline { 2 - 6 } & Time & $\mathbf{2 4} \mathbf{~ h r s ~}$ & $\mathbf{2 4} \mathbf{~ h r s}$ & $\mathbf{2 4} \mathbf{~ h r s}$ & $\mathbf{2 4} \mathbf{~ h r s}$ \\
\hline 1 & Warp & $772 \mathrm{~N}$ & $810 \mathrm{~N}$ & $845 \mathrm{~N}$ & $910 \mathrm{~N}$ \\
2 & Warp & $772 \mathrm{~N}$ & $810 \mathrm{~N}$ & $845 \mathrm{~N}$ & $910 \mathrm{~N}$ \\
3 & Warp & $772 \mathrm{~N}$ & $810 \mathrm{~N}$ & $846 \mathrm{~N}$ & $912 \mathrm{~N}$ \\
4 & Warp & $771 \mathrm{~N}$ & $811 \mathrm{~N}$ & $840 \mathrm{~N}$ & $908 \mathrm{~N}$ \\
5 & Warp & $771 \mathrm{~N}$ & $809 \mathrm{~N}$ & $846 \mathrm{~N}$ & $910 \mathrm{~N}$ \\
& Mean warp & $\mathbf{7 7 1 . 6 0 N}$ & $\mathbf{8 1 0 N}$ & $\mathbf{8 4 4 . 4 0 N}$ & $\mathbf{9 1 0 N}$ \\
1 & Weft & $680 \mathrm{~N}$ & $730 \mathrm{~N}$ & $760 \mathrm{~N}$ & $819 \mathrm{~N}$ \\
2 & Weft & $682 \mathrm{~N}$ & $731 \mathrm{~N}$ & $765 \mathrm{~N}$ & $825 \mathrm{~N}$ \\
3 & Weft & $679 \mathrm{~N}$ & $729 \mathrm{~N}$ & $761 \mathrm{~N}$ & $820 \mathrm{~N}$ \\
4 & Weft & $678 \mathrm{~N}$ & $727 \mathrm{~N}$ & $755 \mathrm{~N}$ & $817 \mathrm{~N}$ \\
5 & Weft & $683 \mathrm{~N}$ & $733 \mathrm{~N}$ & $758 \mathrm{~N}$ & $816 \mathrm{~N}$ \\
& Mean Weft & $\mathbf{6 7 9 . 8 N}$ & $\mathbf{7 3 0 N}$ & $\mathbf{7 5 9 . 8 N}$ & $\mathbf{8 1 9 . 4 N}$ \\
\hline
\end{tabular}

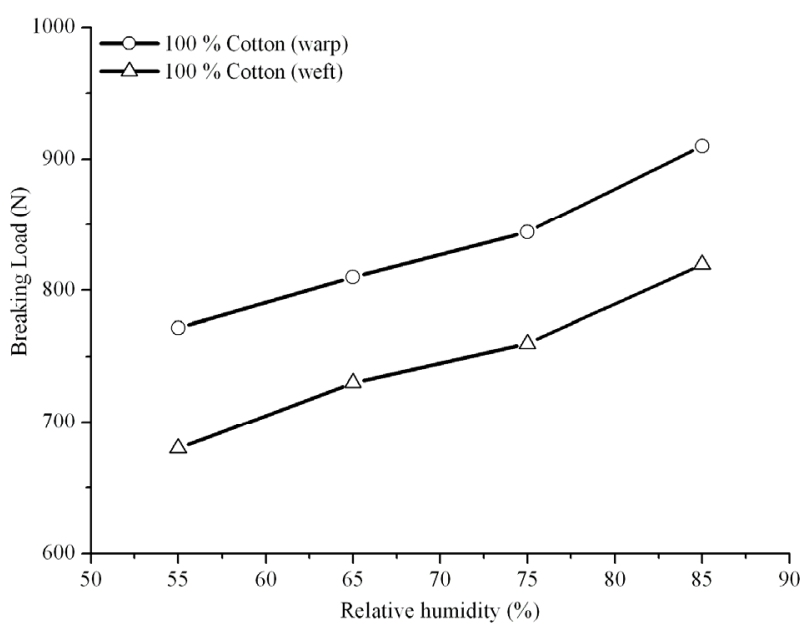

Figure 1. Tensile strength of cotton in warp and weft direction at different $R H$ values. 
increases its strength. Fundamentally, it is due to the decrease in cohesive force between the chain molecules due to swelling and the release of internal strain by swelling. Thus in the native cellulosic fiber, such as cotton, the release of internal strain between the long chain molecules predominant and this increase the fiber strength because of a more uniform internal distribution of stress. Also the average chain length (DP) in cotton is five times greater than regenerated cellulose, so that the individual molecules in cotton may be expected to have more point of adhesion and so to process greater internal strain [10]. In its mature dried form, nearly 90 per cent by weight of the cotton fibre is cellulose. In fact the cellulose found in cotton fibres is the purest form of cellulose found in all plants. The cellulose in cotton fibres is mostly (88 - 96.5 per cent). The non-cellulose components (4 - 12 per cent) are located either on the outer layers of the cotton fibre in the cuticle and primary cell wall or inside the residual protoplasm called the lumen. The secondary wall of mature fibres is primarily cellulose in its most highly crystalline and oriented form Figure 2 shows the structure of the cellulose molecules in cotton. From a physical viewpoint the molecule is a ribbon-like structure of linked six-member rings each with three hydroxyl groups $(\mathrm{OH})$ on the C2, C3 and C6 atoms projecting out of the plane of the ribbon. As well as providing structural stability the hydroxyl groups allow extensive intermolecular hydrogen bonding with many molecules, including water. The accessibility of water to these hydroxyl groups depends on the spacing between crystal lattice planes. From a completely dry state, water molecules will form hydrogen bonds with hydroxyl groups that are not already linked within crystalline regions [11].

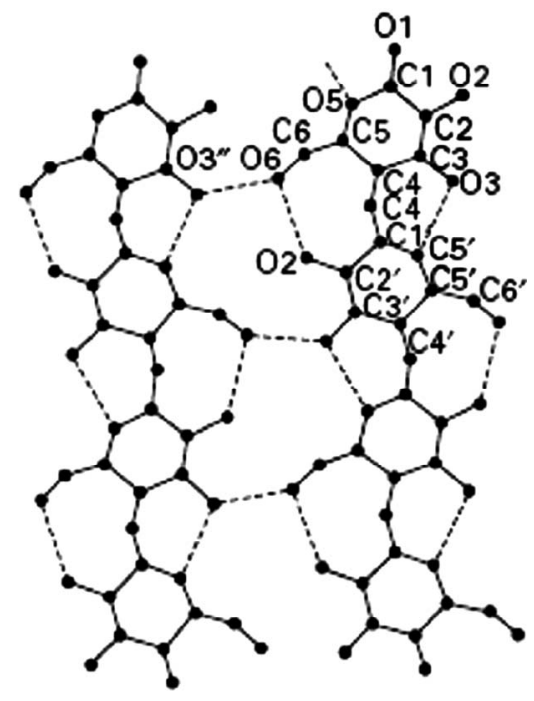

Figure 2. Assembly of cellulose molecules in a sheet. Hydrogen bonds are shown by dotted lines. Circled carbon atoms; C2, C3 and C6, show location of hydroxyl (-OH) groups.
As indicated from Table 3 and Figure 3, the silk fabric shows a reverse result as compared to cotton, as we move from $55 \%$ towards $85 \%$ R.H, the tensile strength determined were gradually decreased. The silk fiber are linear, fibroin polymer that forms a chemical point of view, differ from wool fiber due to their different amino acid composition. More precisely, silk fiber does not contain disulphide bonds. This Chemical difference may affect the morphology of the crystal, producing only the $\beta$-configuration, which together with the high degree of crystallinity is responsible for high tensile strength of silk fiber. In wet conditions the tensile strength of silk fiber decreases because water molecules hydrolyze a significant number of hydrogen bond [12]. Silk is a natural fiber secreted as a continuous filament by the silk worm,

Table 3. For silk (tensile strength both in warp \& weft direction at different RH values).

\begin{tabular}{cccccc}
\hline & RH & $\mathbf{5 5 \%}$ & $\mathbf{6 5 \%}$ & $\mathbf{7 5 \%}$ & $\mathbf{8 5 \%}$ \\
\cline { 2 - 6 } $\mathbf{S} \#$ & Temperature & $\mathbf{2 1}{ }^{\circ} \mathbf{C}$ & $\mathbf{2 1}{ }^{\circ} \mathbf{C}$ & $\mathbf{2 1}^{\circ} \mathbf{C}$ & $\mathbf{2 1}{ }^{\circ} \mathbf{C}$ \\
\cline { 2 - 6 } & Time & $\mathbf{2 4} \mathbf{~ h r s}$ & $\mathbf{2 4} \mathbf{~ h r s}$ & $\mathbf{2 4} \mathbf{~ h r s}$ & $\mathbf{2 4} \mathbf{h r s}$ \\
\hline 1 & Warp & $512 \mathrm{~N}$ & $480 \mathrm{~N}$ & $452 \mathrm{~N}$ & $407 \mathrm{~N}$ \\
2 & Warp & $510 \mathrm{~N}$ & $480 \mathrm{~N}$ & $450 \mathrm{~N}$ & $410 \mathrm{~N}$ \\
3 & Warp & $508 \mathrm{~N}$ & $478 \mathrm{~N}$ & $449 \mathrm{~N}$ & $409 \mathrm{~N}$ \\
4 & Warp & $514 \mathrm{~N}$ & $483 \mathrm{~N}$ & $453 \mathrm{~N}$ & $405 \mathrm{~N}$ \\
5 & Warp & $512 \mathrm{~N}$ & $480 \mathrm{~N}$ & $452 \mathrm{~N}$ & $403 \mathrm{~N}$ \\
& Mean Warp & $\mathbf{5 1 1 . 2 0 N}$ & $\mathbf{4 8 0 . 2 0 N}$ & $\mathbf{4 5 1 . 2 0 N}$ & $\mathbf{4 0 6 . 8 N}$ \\
1 & Weft & $463 \mathrm{~N}$ & $441 \mathrm{~N}$ & $414 \mathrm{~N}$ & $368 \mathrm{~N}$ \\
2 & Weft & $465 \mathrm{~N}$ & $444 \mathrm{~N}$ & $416 \mathrm{~N}$ & $370 \mathrm{~N}$ \\
3 & Weft & $462 \mathrm{~N}$ & $445 \mathrm{~N}$ & $418 \mathrm{~N}$ & $371 \mathrm{~N}$ \\
4 & Weft & $466 \mathrm{~N}$ & $438 \mathrm{~N}$ & $412 \mathrm{~N}$ & $365 \mathrm{~N}$ \\
5 & Weft & $460 \mathrm{~N}$ & $440 \mathrm{~N}$ & $413 \mathrm{~N}$ & $367 \mathrm{~N}$ \\
& Mean Weft & $\mathbf{4 6 3 . 2 0 N}$ & $\mathbf{4 4 1 . 6 N}$ & $\mathbf{4 1 4 . 6 N}$ & $\mathbf{3 6 8 . 2 N}$ \\
\hline
\end{tabular}

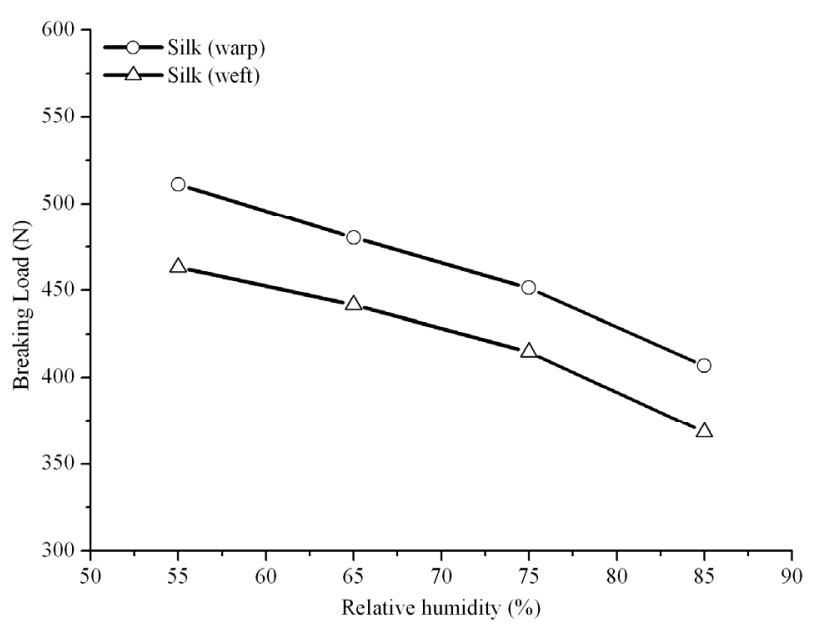

Figure 3. Tensile strength of silk in warp and weft direction at different RH values. 
Bombyx mori. Silk consists essentially fibroin polymer and in the raw state coated with a gum Sericin that is usually removed before spinning. The silk polymer is composed of 16 different amino acids linked with peptide bonds. The important chemical groups of the silk polymer are the peptide groups which gives rise to hydrogen bonds, and the carboxyl and amine groups which gives rise to the salt linkages. The silk filament is strong. This strength is due to its linear, $\beta$-configuration polymer and very crystalline polymer system. These two factors permit more hydrogen bonds to be formed in a much regular manner. When wet silk losses its strength. This is due to water molecules hydrolyzing a significant number of hydrogen bonds and in the process weakening the silk polymer. The greater crystalline of silk polymer system allows fewer molecules enter into the polymer system of silk [13].

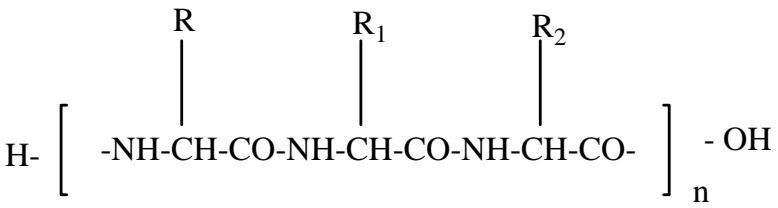

The general formula for the polypeptide polymer. Depending upon the type of radical $R, R_{1}, R_{2}$, the polypeptide polymer would be identical either as being a silk fibroin polymer or a wool keratin polymer.

The results obtained from Table 4 and Figure 4, polyester fabric shows that it is strong to very strong fabric because of their extremely crystalline polymer system. This allows the formation of very effective Van der Waals forces as well as the very weak hydrogen bond, resulting in very good tensile properties one associated with polyester polymer. The tensile strength of polyester fiber remains unaltered when we passes from $55 \%$ to $85 \% \mathrm{RH}$. This occurs because of the completely hydrophobic and extremely crystalline polyester polymer system, which resists the entry of water molecules to any significant extant [14].

Polyester fiber is the condensation polymerization product of ethylene glycol and terepthalic acid. The word ester is the name given to salt formed from the reaction between an alcohol and an acid. Ester is organic salt and polyester means many organic salts. Chemically it is a polymer of polyethylene glycol terphlate. The important chemical groups in the polyester polymer are the ethylene group, - $\mathrm{CH}_{2}$, the slightly polar carbonyl group, -CO-, and the ester group, -OCO- group. The one of the distinguishing characteristics of polyester is attributed to the benzene rings in the polymer chain. The aromatic character leads to chain stiffness, preventing the deformation of disordered regions, which results in weak Van der Waals interaction forces between chains. The aromatic, carboxyl and aliphatic molecular groups are nearly planar in configuration and exist in a side-by-side arrangement. The cohesion of polyester chains is a result of hydrogen bonds and van der Waals interactions, caused by dipole interaction, induction and dispersion forces among the chains. The insignificant amount of moisture, which may be present in polyester textile materials, exists as a molecular film of water on the surface of filaments of staple fiber [15].

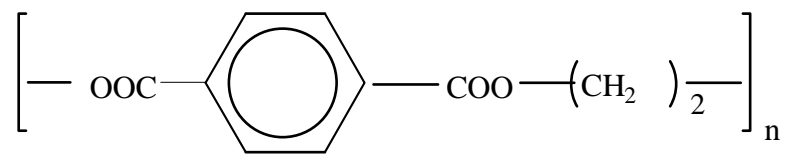

Polyethylene Terpthlate

Table 4. For polyester (Tensile Strength both in warp \& weft direction at different $R H$ values).

\begin{tabular}{|c|c|c|c|c|c|}
\hline \multirow{3}{*}{ S \# } & $\mathrm{RH}$ & $55 \%$ & $65 \%$ & $75 \%$ & $85 \%$ \\
\hline & Temperature & $21^{\circ} \mathrm{C}$ & $21^{\circ} \mathrm{C}$ & $21^{\circ} \mathrm{C}$ & $21^{\circ} \mathrm{C}$ \\
\hline & Time & 24 hrs & 24 hrs & 24 hrs & 24 hrs \\
\hline 1 & Warp & $935 N$ & $942 \mathrm{~N}$ & $937 N$ & $939 N$ \\
\hline 2 & Warp & $936 \mathrm{~N}$ & $945 N$ & $939 N$ & $937 N$ \\
\hline 3 & Warp & $938 \mathrm{~N}$ & $944 N$ & $940 \mathrm{~N}$ & $936 \mathrm{~N}$ \\
\hline 4 & Warp & $933 N$ & $939 N$ & $934 \mathrm{~N}$ & $940 N$ \\
\hline \multirow[t]{2}{*}{5} & Warp & $934 \mathrm{~N}$ & $941 N$ & $935 N$ & $942 \mathrm{~N}$ \\
\hline & Mean warp & $935.2 \mathrm{~N}$ & $942.2 \mathrm{~N}$ & $937 N$ & $938.8 \mathrm{~N}$ \\
\hline 1 & Weft & $860 N$ & $864 N$ & $862 \mathrm{~N}$ & $863 N$ \\
\hline 2 & Weft & $861 N$ & $866 \mathrm{~N}$ & $866 \mathrm{~N}$ & $864 N$ \\
\hline 3 & Weft & $857 \mathrm{~N}$ & $864 N$ & $868 N$ & $867 N$ \\
\hline 4 & Weft & $859 N$ & $867 N$ & $857 N$ & $859 N$ \\
\hline \multirow[t]{2}{*}{5} & Weft & $863 N$ & $858 N$ & $858 N$ & $861 \mathrm{~N}$ \\
\hline & Mean Weft & $860 \mathrm{~N}$ & $863.8 \mathrm{~N}$ & $862.2 \mathrm{~N}$ & $862.8 \mathrm{~N}$ \\
\hline
\end{tabular}

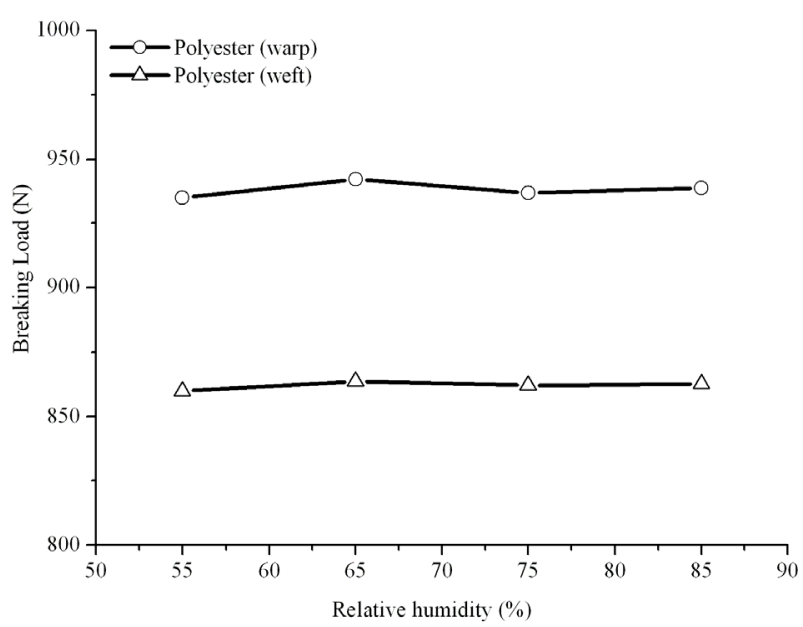

Figure 4. Tensile strength of polyester in warp and weft direction at different $R H$ values. 
Figures 5(a) and (b) indicates the combined effect of Tensile Strength both in Warp and Weft direction of silk, cotton and polyester at different RH values. It has been also observed that the tensile strength calculated in weft direction for each cotton, polyester and silk fiber comes out to be minimum as compared to the warp direction, furthermore fluctuation in the RH have no significant effect on tensile results of polyester fabric and a pronounced effect were found in case of cotton and silk fiber.

All fibers, whether hydrophilic or hydrophobic, absorb some water from an atmosphere having a relative humidity above $0 \%$. The amount of moisture contained by a fiber when its own relative humidity is equal to that of the surrounding atmosphere, and the point at which fiber will neither gain nor lose moisture to the atmosphere is called equilibrium moisture content. The equilibrium moisture content will remain unchanged unless the relative

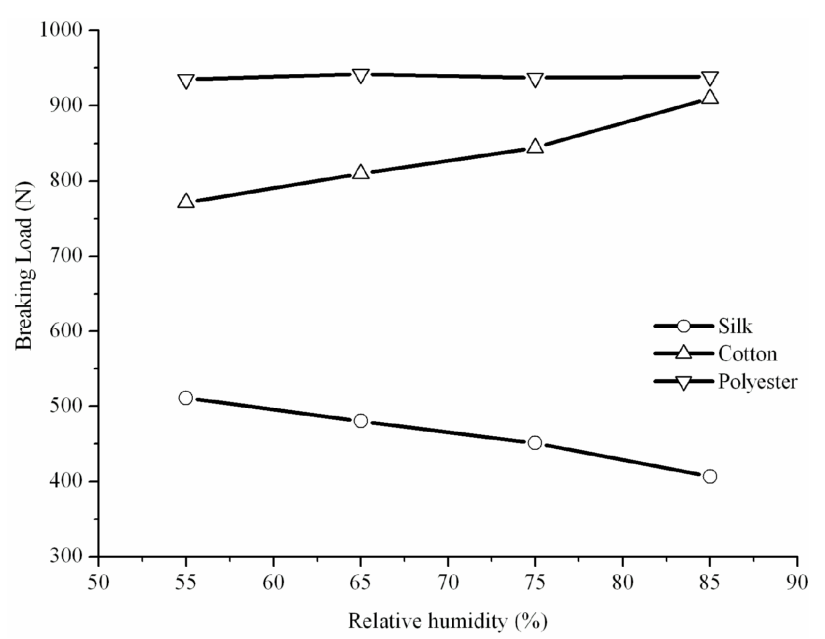

(a)

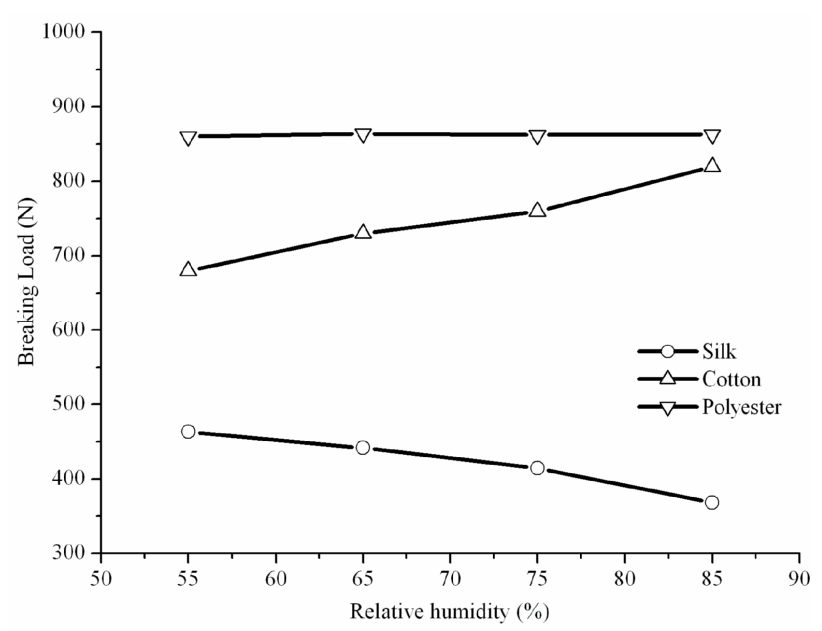

(b)

Figure 4. (a) Combined effect of Tensile Strength in Warp direction at different RH values; (b) Combined effect of Tensile Strength in Weft direction at different $R H$ values. humidity is changed; lowering the relative humidity of the environment will result in the fiber losing moisture until new equilibrium moisture content is reached. Similarly, increasing the relative humidity of the environment will result in the fiber gaining moisture until new equilibrium moisture content is reached.

Relative humidity $(\mathrm{RH})$ governs the amount of moisture contained in materials at equilibrium with the environment. This is almost independent of temperature. As relative humidity changes, the object's water content adjusts to the new relative humidity level, creating a new equilibrium. At higher $\mathrm{RH}$, there is more water in fiber [16].

Silk and cotton are hydrophilic fibers, meaning that their surface has bonding sites for water molecules. Therefore, water tends to be retained in the hydrophilic fibers, which have poor moisture transportation and release; they have the ability to absorb moisture from the surroundings. At equilibrium the moisture content of silk is about $11 \%$ and that of cotton is about $8 \%$. Polyester is a hydrophobic fiber; meaning that their surface has few bonding sites for water molecules. Hence, they tend not to get wet and have good moisture transportation and release. Its moisture content is low as $0.4 \%$, it absorbs moisture very slowly and dries quickly. Cotton and silk absorbs moisture very quickly but dries slowly. As the relative humidity (RH) of the surrounding increases, the moisture absorption also increases and as the relative humidity decreases the drying of fibers or "Desorption" takes place [17].

If two identical samples of fibre, one wet and one dry, are placed in a standard atmosphere of $65 \% \mathrm{RH}$, it might be expected that they would both eventually reach the same value of regain. However, this is not the case as the one that was originally wet is found to have a higher regain than the one that was originally dry; this difference is due to hysteresis between moisture uptake and moisture loss [18].

Exposure to moisture for prolonged period of time may cause to degradate the textile fibes. Under higher humid conditions for prolonged period of time may cause to change the dimension, texture and shape of the textile fibers. As the relative humidity decreases, desorption or drying of textile fibers takes place. It is not reversible under drying conditions, because under lower humidity conditions some textile fibers may losses and some increases their strength. Controlled humid conditions are required for particular fabric [19].

\section{Conclusion}

The present research work has demonstrated that textile samples exhibits often significant change in tensile strength testing as relative humidity fluctuates around the recommended standard condition of $65 \% \mathrm{RH}$. In case of 
synthetic fiber polyester, we found no significant difference in tensile properties due to the hydrophobic character of this fiber. In natural fiber cotton we found a pronounced effect in tensile properties by fluctuate the relative humidity from $65 \%$ to $85 \%$. In cotton the tensile strength gradually increases. The silk fiber shows a reverse result as compared to cotton, the tensile strength decreases as we passes from $65 \%$ to $85 \% \mathrm{RH}$. It is recommended that environmental conditions must be specified and continually controlled so as to minimize tensile strength results variation for all samples to be evaluated.

\section{REFERENCES}

[1] B. P. Saville, "Physical Testing of Textile," 1st Edition, CRC Press, Boca Raton, 1999.

[2] J. E. Booth, "Principal of Textile Testing," 3rd Edition, Chemical Publishing Corporation, Michigan, 1984.

[3] K. Craven Brown, J. Cameron Mann and F. Thomas Peirce, "The Influence of Humidity on the Elastic Properties of Cotton Part-V, The Tensile Behavior," The Journal of Textile Institute, Vol. 21, No. 4, 1930, pp. 186-204.

[4] J. E. Booth, "Principal of Textile Testing," 3rd Edition, Chemical Publishing Corporation, Michigan, 1984.

[5] ASTM D-1776, Textile Standard Atmosphere for Conditioning and Testing, 1998.

[6] J. E. Mclntyre, “Textile Terms \& Definition,” 10th Edition, Textile Institute, Manchester, 1990.

[7] ISO-13934-1, “Tensile Properties of Fabric-Part-1, Determination of Maximum Force and Elongation using Strip Method,” 1999.

[8] ISO-3801, "Determination of Mass per Unit Length and Mass per Unit Area,” 1977.
[9] ISO-7211-2, "Determination of Number of Threads per unit Length,” 1984.

[10] R. Meredlth, "Moisture in Textile,” 1st Edition, Textile Book Publication, New York, 1960.

[11] T. P .Nevell and S. H. Zeronian, "Cellulose Chemistry and Its Applications,” Ellis Horwood, Chichester, UK, 1985.

[12] E. P. Gohl, "Textile Science," An Explanation to the Fiber Properties," 2nd Edition, Longman Cheshire, Melbourne, 1993.

[13] O. Ahumada, M. Cocca and G. Gentile, “Uniaxial Tensile Properties of Yarns: Effects of Moisture Level on the Shape of Stress-Strain Curves,” Textile Research Journal, Vol. 74, No. 11, 2004, pp. 1001-1006. doi: $10.1177 / 004051750407401111$

[14] E. P. Gohl, "Textile Science, An Explanation to the Fiber Properties,” 2nd Edition, Longman Cheshire, Melbourne, 1993.

[15] R. W. Moncrieff, “Man-Made Fibers,” 6th Edition, Newnes-Butterworths, UK, 1975.

[16] J. F. Fuzek, “Absorption and Desorption of Water by Some Common Fibers," Journal of Industrial and Engineering Chemistry Product and Research Development, Vol. 24, No. 14, 1985, pp. 140-144. doi:10.1021/i300017a026

[17] X. W. Chen, J. Q. Fu., W. Z. Li and X. S. Gao, "Moisture Absorption and Release Performance of Fabrics," Journal of Clothing Technology, Vol. 25, No. 4, 2005, pp. 48-56

[18] B. P. Saville, "Physical Testing of Textile,” 1st Edition, CRC Press, Boca Raton, 1999.

[19] A. Barbra, "Environmental Monitoring and Control," 1991.

http://cool.conservation-us.org/bytopic/environment/inde x.html 